\title{
Sınıf ve Okul Öncesi Öğretmen Adaylarının Çokkültürlü Eğitime Yönelik Tutumları ile Kültürlerarası Duyarlılıkları Arasındaki İlişsi: Uludağ Üniversitesi Örneği*
}

\author{
The Relationship Between The Attitudes of Classroom and \\ Preschool Teacher Candidates Towards Multicultural \\ Education and Their Intercultural Sensitivities: Sample of \\ Uludag University
}

\author{
Gönül ONUR SEZER**, Pınar BAĞÇELİ KAHRAMAN***
}

Öz: Bu araştırmada, sınıf ve okul öncesi öğretmenliği öğretmen adaylarının çokkültürlü eğitime yönelik tutumları ile kültürlerarası duyarlılıkları arasındaki ilişkinin incelenmesi amaçlanmıştır. Bu amaç doğrultusunda öğretmen adaylarının öğrenim gördükleri anabilim dalı ve büyüdükleri yerleşim yeri değişkenlerine göre çokkültürlü eğitime yönelik tutumları ve kültürlerarası duyarlılıklarında farklılık olup olmadığı incelenmiştir. Araştırmada durum saptamaya yönelik genel tarama modeli kullanılmıștır. Çalışma grubu Uludağ Üniversitesi Eğitim Fakültesine devam eden 110 sınıf ve 103 okul öncesi öğretmenliği öğretmen adaylarından oluşmaktadır. Araştırmada kişisel bilgi formu, Çok Kültürlü Eğitime Yönelik Tutum Ölçeği ve Kültürlerarası Duyarlılık Ölçeği kullanılmıştır. Öğretmen adaylarının çok kültürlü eğitime yönelik tutumlarını ve kültürlerarası duyarlılık düzeylerinin belirlenmesi amacıyla yapılan Kolmogorov-Smirnov normallik testi sonucunda dağılımın normal olmadığı saptanmıştır. Bu nedenle Kruskall Wallis-H (KWH) ve Mann Whitney U (U) testleri uygulanmıştır. Ayrıca öğretmen adaylarının çokkültürlü eğitime yönelik tutumları ile kültürlerarası duyarlılıkları arasındaki ilişki korelasyon analizi yöntemi ile analiz edilmiştir. Araştırma sonucunda sınıf ve okul öncesi öğretmenliği öğretmen adaylarının çok kültürlü eğitime yönelik tutumları ile kültürlerarası duyarlılık düzeyleri arasında pozitif yönde anlamlı bir ilişki olduğu tespit edilmiştir. Ayrıca öğretmen adaylarının çok kültürlü eğitime yönelik tutumları ve kültürlerarası duyarlılık düzeylerinin öğrenim gördükleri anabilim dalına ve büyüdükleri yerleşim yerine göre anlamlı bir farklılığa yol açmadığı tespit edilmiştir.

Anahtar Kelimeler: Çokkültürlü eğitim, kültürlerarası duyarlı1ık, sınıf öğretmenliği programı, okul öncesi öğretmenliği programı, öğretmen adayları

\begin{abstract}
The purpose of this study is to investigate the relationship between the attitudes of preschool and classroom teacher candidates towards multicultural education and their intercultural sensitivity. With this aim the attitudes of teacher candidates towards multicultural education according to their departments and surrounding environment is analyzed and determined if there is a difference between their intercultural sensitivities. General screening model was used in the research. The sample of the research was formed of 110 classroom and 103 preschool teacher candidates studying at Uludag University Faculty of Education. Personal Information Form, Multicultural Education Attitude Scale and Intercultural Sensitivity Scale were used. The distribution was determined to be normal as a result of Kolmogorov-Smirnov normality test. Therefore, Kruskall Wallis-H $(\mathrm{KWH})$ and Mann Whitney U (MWU) test was used. Also, correlation analysis was used in order to determine the relationship between the attitudes of classroom and preschool teacher candidates towards multicultural education and their intercultural sensitivity levels. It was determined as a result of the study that the attitudes of classroom and preschool teacher candidates towards multicultural education and their intercultural sensitivities are

\footnotetext{
*Bu araştırma 11-14 Mayıs 2016 Muğla'da düzenlenen 15. Uluslararas1 Sınıf Öğretmenliğgi Eğitimi Sempozyumu'nda sözlü bildiri olarak sunulmuştur.

**Yrd. Doç. Dr., Uludă̆ Üniversitesi Eğitim Fakültesi, Temel Eğitim Bölümü, Sınıf Eğitimi Anabilim Dalı, Bursa, Türkiye, e-posta: gonulonur@uludag.edu.tr

***Yrd. Doç. Dr., Uludağ Üniversitesi Eğitim Fakültesi, Temel Eğitim Bölümü, Okul Öncesi Eğitimi Anabilim Dalı, Bursa, Türkiye, e-posta: pinarbag@uludag.edu.tr
} 
high and there is a significant relation between these two attitudes in a positive way. A significant difference wasn't found between the attitudes of teacher candidates towards multicultural education and their intercultural sensitivity levels according to their departments and surrounding environment.

Keywords: Multicultural education, intercultural sensitivity, classroom teachers' program, preschool teachers' program, teacher candidates.

\section{Giriş}

Çok kültürlülük, bireylerin sosyal sınıf, yaş, engelli olma, dil, etnik köken, din ve kültürel farklılıklarının bir arada yaşanması olarak tanımlanırken, bu farklılıklardan gelen öğrencilerin eşit şartlarda eğitim görmeleri ve buna yönelik olarak okul ortamının yapılandırılması süreci de çokkültürlü eğitim olarak ifade edilmektedir (APA, 2002; Cirık, 2008).

Çokkültürlü eğitim ortamının oluşturulmasında bireylerin farklılıklarına saygı duyulması, çocukların farkındalık düzeylerinin ve kültürlerarası duyarlılıklarının arttırılmasına yönelik çalışmaların yürütülmesi gerekmektedir (Mahiroğulları, 2005). Kültürlerarası ilişkiler açısından olumlu duygular geliştirebilme, kültürel farklılıkları tanımlayabilme ve değerlendirebilme, uygun ve etkili davranış geliştirebilme kültürlerarası duyarlılık olarak karşımıza çıkmaktadır. Bireylerin kültürlerarası duyarlılığının olması; bireyler arasındaki farklılıkların anlaşılmasına, onaylanmasına ve kabul edilmesine olanak sağlamaktadır. Ayrıca bu bireyler motivasyonu yüksek, özsaygıll, özdenetimli, açık fikirli ve empati kurabilen özelliklere de sahiptirler (Chen ve Starosta, 2000; Üstün, 2011). Küresel düzeyde sorumluluklarını bilen, bu sorumluluklarını üstlenen, takım çalışmasına yatkın, ulusal değerleri özümseyen bir gençlik yetiştirmek eğitim sisteminin değişen ve dönüşen işlevinde çağın gereği olarak öne çıkan yeterliliklerdir. Ayrıca barış içinde bir dünya için dünyaya açık, kendine güveni olan, eşitliği savunan ve kültürel zenginliğe sahip öğrencilerin yetiştirilmesi de amaçlanmaktadır (Balay, 2004).

Farklı kültürel özellikleri bir arada barındıran okullarda, farklı kültürel özelliklerdeki öğretmenler ile öğrenciler etkileşim içinde eğitime devam etmektedirler. Bu ortamlarda kültürel farklılıklardan dolayı olumsuzluklar ortaya çıkabilmektedir. Önemli olan farklı kültürlerin dikkate alındığı bir eğitim anlayışının sürdürülmesidir. Bu noktada en önemli görevi, öğretmenler üstlenmektedir. Öğretmen; eğitim programını uygulayan, değerlendirme işini yapan ve öğrenme ortamını oluşturan kişidir (Polat, 2009, Rengi ve Polat, 2014). Okul öncesi eğitimden başlayarak firsat eşitliğinin sağlanması ve öğrencilerin akademik ve sosyal gelişimlerinin desteklenmesi ancak öğrencilerin farklılıklarına duyarlı olarak ve sinıfta demokratik bir ortam oluşturularak gerçekleştirilebilmektedir (Ünlü ve Örten, 2013). Öğrenme ortamının demokratik olması, öğrencilerin farklı olduklarının bilincinde olunması ve bu duruma sayg1 gösterilmesi ile sağlanabilmektedir. Bununla beraber, öğretmenlerin kültürlerarası duyarlılığa sahip olması, kültürel özellikleri farklı öğrencilerin bir araya getirilme becerisini taşımasını da gerektirmektedir (Rengi ve Polat, 2014). Bu nedenle öğretmen yetiştiren kurumlarda öğretmen adaylarının farklı kültürlere saygılı ve duyarlı bireyler olmaları konusunda desteklenmeleri gerekmektedir. Yapılan araştırmalar incelendiğinde çokkültürlü eğitime yönelik olarak yapılmış çeşitli ölçek çalışmaları ve araştırmalar olduğu görülmektedir (Başbay ve Kağnıcı, 2011; Cırık, 2008; Çoban, Karaman ve Doğan, 2010; Jimenez, Guzman ve Maxwell, 2014; Kaya ve Söylemez, 2014; Özdemir ve Dil, 2013; Polat, 2009; Polat ve Barka, 2014; Sharma, 2005; Tortop, 2014; Van Oudenhoven ve Van der Zee, 2002; Yavuz ve Anıl, 2010; Yazıcı, Başol ve Toprak, 2009). Ancak bu araştırmaların sınırlı düzeyde olduğu söylenebilir. Araştırmalar, yeterli bilgi ve beceriye sahip olmayan öğretmenlerin kültürel farklılıklardan gelen öğrencilere yeni öğrenme ortamını düzenlemede yetersiz kaldıklarını göstermektedir (Cırık, 2008; Çoban, Karaman ve Doğan, 2010; Gay, 2002; Keengwe, 2010; Neuharth-Pritchett, Reiff ve Pearson 2001; Polat, 2009). Eğitim fakültelerinin öğretim elemanlarıyla yapılan bir çalışma sonucunda, öğretim elemanlarının kültürel farklılıkları bulunan öğrencilerle sıklıkla bir arada bulundukları, çok kültürlü eğitimin gerekliliğine inandıkları, ancak uygulamada problem yaşadıkları saptanmıştır (Smolen, Colville-Hall, Liang ve Mac Donald, 2006). Bu problemlerin çözülebilmesi için, öğretmenlerin kültürel farklılıkları olan öğrencilere ilişkin duyarlılıklarının 
arttırılması ve ögretmenlere bu öğrencilerin öğrenme ortamlarının düzenlenmesine yönelik bilgi ve becerinin kazandırılması oldukça önemlidir. Bu araştırmada sınıf ve okul öncesi öğretmenliği öğretmen adaylarının çokkültürlü eğitime yönelik tutumları ile kültürlerarası duyarlılıkları arasındaki ilişkinin incelenmesi amaçlanmıştır. Ayrıca öğretmen adaylarının büyüdükleri yerleşim yeri ve öğrenim gördükleri anabilim dalına göre çokkültürlü eğitime yönelik tutumları ve kültürlerarası duyarlılıklarında farklılık olup olmadığının incelenmesi araştırmanın bir diğer amacidır.

\section{Yöntem}

\section{Araştırma modeli}

$\mathrm{Bu}$ araştırmada öğretmen adaylarının çok kültürlü eğitime yönelik tutumları ile kültürlerarası duyarlılık düzeyleri arasındaki ilişkinin belirlenmesi amacıyla durum saptamaya yönelik olarak genel tarama modeli kullanılmıştır.

\section{Çalışma Grubu}

Tablo 1'de araştırmaya katılan öğretmen adaylarına ilişkin demografik bilgiler yer almaktadır.

Tablo 1

Örneklem Grubuna İlişkin Demografik Bilgiler

\begin{tabular}{llllllll}
\hline & & \multicolumn{2}{l}{ Sinıf Ö̆̆retmenliği } & \multicolumn{2}{c}{ Okul öncesi } & \multicolumn{2}{c}{ Toplam } \\
& & $\mathrm{f}$ & $\%$ & $\mathrm{f}$ & $\%$ & $\mathrm{f}$ & $\%$ \\
\hline \multirow{2}{*}{ Cinsiyet } & Kiz & 94 & 85.5 & 91 & 88.3 & 185 & 86.9 \\
& Erkek & 16 & 14.5 & 12 & 11.7 & 28 & 13.1 \\
& Toplam & 110 & 51.6 & 103 & 48.4 & 213 & 100 \\
\hline \multirow{3}{*}{ Yerleşim Yeri } & Köy & 16 & 14.5 & 14 & 13.6 & 30 & 14.1 \\
& İlçe & 48 & 43.6 & 40 & 31.8 & 88 & 41.3 \\
& İl & 46 & 41.8 & 49 & 47.6 & 95 & 44.6 \\
& Toplam & 110 & 51.6 & 103 & 48.4 & 213 & 100 \\
\hline
\end{tabular}

Araştırmanın çalışma grubunu basit seçkisiz örnekleme yöntemi ile seçilen (Büyüköztürk, Çakmak, Akgün, Karadeniz ve Demirel, 2016) Uludağ Üniversitesi Eğitim Fakültesinde öğrenim görmekte olan, 110 sınıf öğretmenliği öğretmen adayı ile 103 okul öncesi öğretmenliği öğretmen adayı oluşturmaktadır. 213 öğretmen adayının verileri üzerinde istatistiksel işlemler yapılmıştır.

\section{Veri Toplama}

Kişisel Bilgi Formu

Yapılan diğer çalışmalar da incelenerek ve uzman görüşü alınarak öğretmen adaylarının cinsiyet, bölüm, büyüdüğü yerleşim birimine ilişkin soruların yer aldığı kişisel bilgi formu oluşturulmuştur.

\section{Çok Kültürlü Ĕ̈itime İlişkin Tutum Ölçeği}

Ponterotto, Baluch, Greig, ve Rivera (1998) tarafindan geliştirilen Çokkültürlü Eğitime İlişkin Tutum Ölçeği, Yazıcı, Başol ve Toprak (2009) tarafından Türkçeye uyarlanmıştır. Beşli likert tipinde 20 maddeden oluşan ölçeğin Cronbach Alpha katsayısı .74'tür. Yapılan bu çalışmada da Cronbach Alpha katsayısı .71 olarak belirlenmiştir. Ölçekten elde edilen puanlar yükseldikçe bireyin olumlu tutuma sahip olduğu söylenebilir.

Kültürlerarası Duyarlılık Ölçeği

"Kültürlerarası Duyarlılık Ölçeği" Chen ve Starosta (2000) tarafindan geliştirilmiştir. Üstün (2011) tarafindan Türkçeye uyarlanan bu ölçek beşli likert tipinde 24 maddeden oluşmaktadır. 
Kültürlerarası etkileşimde özgüven, kültürlerarası etkileşime özen gösterme, kültürel farkl11ıklara saygı duyma, kültürlerarası etkileşime katılım ve kültürlerarası etkileşimden zevk alma olmak üzere beş boyuttan oluşmaktadır. Üstün (2011) tarafindan yapılan geçerlik çalışması sonucunda ölçek tek boyutlu bir yapı almış ve 23 maddeye indirilmiştir. Ölçeğin Cronbach Alpha katsayısı .90 olarak belirlenmiştir. Bu araştırmada da Cronbach Alpha katsayısı .74 olarak belirlenmiştir.

\section{Verilerin Analizi}

Verilerin analiz süreci iki aşamada gerçekleştirilmiştir. Birinci aşamada normallik açısından değerlendirilmiş, sonraki aşamada ise, alt problemler incelenmiştir. Yapılan KolmogorovSmirnov normallik testi sonucunda çok kültürlü eğitime ilişkin tutum $(\mathrm{p}=.001)$ ve kültürlerarası duyarlılık ( $\mathrm{p}=.005)$ ölçeklerinin dağılımının normal olmadığı belirlenmiştir Bu nedenle Kruskall Wallis-H (KWH) ve Mann Whitney U (U) testleri uygulanmıştır. Ayrıca sınıf ve okul öncesi öğretmenliği öğretmen adaylarının çok kültürlü eğitime yönelik tutumları ile kültürlerarası duyarlılık düzeyleri arasındaki ilişkinin belirlenmesi amacıyla korelasyon analizi yapılmıştır.

\section{Bulgular}

Sınıf ve okul öncesi öğretmenliği öğretmen adaylarının çokkültürlü eğitime yönelik tutumları ile kültürlerarası duyarlılıkları arasındaki ilişkinin incelendiği bu araştırmada elde edilen veriler aşağıda sunulmuştur.

Öğretmen adaylarının çok kültürlü eğitime yönelik tutumları ve kültürlerarası duyarlılık ölçeklerine ait betimsel istatistikler Tablo 2'de verilmiştir.

Tablo 2

Sınıf ve Okul Öncesi Öğretmenliği Öğretmen Adaylarının Çok Kültürlü Eğitime Yönelik Tutumları ve Kültürlerarası Duyarlılık Ölçeklerine ait Betimsel İstatistik Sonuçları

\begin{tabular}{|c|c|c|c|c|}
\hline Bölüm & & $\mathrm{n}$ & $\bar{X}$ & ss \\
\hline \multirow[t]{2}{*}{ Toplam } & $\begin{array}{l}\text { Çok Kültürlü Eğitime } \\
\text { Yönelik Tutumları }\end{array}$ & 213 & 75.34 & 6.32 \\
\hline & $\begin{array}{l}\text { Kültürlerarası Duyarlılık } \\
\text { Düzeyleri }\end{array}$ & 213 & 73.21 & 6.14 \\
\hline \multirow{3}{*}{$\begin{array}{l}\text { Okul Öncesi } \\
\text { Öğretmenliği }\end{array}$} & Çok Kültürlü Eğitime & 103 & 75.37 & 6.33 \\
\hline & Yönelik Tutumları & & & \\
\hline & $\begin{array}{l}\text { Kültürlerarası Duyarlılık } \\
\text { Düzeyleri }\end{array}$ & 103 & 73.86 & 6.22 \\
\hline \multirow[t]{2}{*}{ Sınıf Öğretmenliği } & $\begin{array}{l}\text { Çok Kültürlü Eğitime } \\
\text { Yönelik Tutumları }\end{array}$ & 110 & 75.32 & 6.34 \\
\hline & $\begin{array}{l}\text { Kültürleraras1 Duyarlılık } \\
\text { Düzeyleri }\end{array}$ & 110 & 72.59 & 6.02 \\
\hline
\end{tabular}

Tablo 2 incelendiğinde öğretmen adaylarının Çok Kültürlü Eğitime Yönelik Tutum Ölçeği'nden aldıkları ortalama puanın 75.34 ve Kültürlerarası Duyarlılık Ölçeği'nden alınan ortalama puanın 73.21 olduğu görülmüştür. Çok Kültürlü Eğitime Yönelik Tutum Ölçeği'nin standart sapması 6.32 ve Kültürlerarası Duyarlılık Ölçeği'nin standart sapması 6.14 olarak tespit edilmiştir.

Öğretmen adaylarının çok kültürlü eğitime yönelik tutumları ile kültürlerarası duyarlılık düzeyleri arasındaki ilişki Tablo 3'de verilmiştir. 
Tablo 3

Sınıf ve Okul Öncesi Öğretmenliği Öğretmen Adaylarının Çok Kültürlü Eğitime Yönelik Tutumları ile Kültürlerarası Duyarlılık Düzeyleri Arasındaki İlişki

$\begin{array}{lll}\text { Bölüm } & \text { Çok Kültürlü Eğitime } & \text { Kültürlerarası Duyarlılık } \\ \text { Yönelik Tutumları } & \text { Düzeyleri }\end{array}$

\begin{tabular}{|c|c|c|c|}
\hline \multirow{2}{*}{ Toplam } & $\begin{array}{l}\text { Çok Kültürlü Eğitime } \\
\text { Yönelik Tutumları }\end{array}$ & 1 & $.463 * *$ \\
\hline & $\begin{array}{l}\text { Kültürlerarası Duyarlılık } \\
\text { Düzeyleri }\end{array}$ & $.463 * *$ & 1 \\
\hline Okul Öncesi & $\begin{array}{l}\text { Çok Kültürlü Eğitime } \\
\text { Yönelik Tutumları }\end{array}$ & 1 & $.568 * *$ \\
\hline Öğretmenliği & $\begin{array}{l}\text { Kültürlerarası Duyarlılık } \\
\text { Düzeyleri }\end{array}$ & $.568 * *$ & 1 \\
\hline Sinif & $\begin{array}{l}\text { Çok Kültürlü Eğitime } \\
\text { Yönelik Tutumları }\end{array}$ & 1 & $.365 * *$ \\
\hline Öğretmenliği & $\begin{array}{l}\text { Kültürleraras1 Duyarlılık } \\
\text { Düzeyleri }\end{array}$ & $.365 * *$ & 1 \\
\hline
\end{tabular}

$* * \mathrm{p}<.001$

Çalı̧̧maya katılan sınıf ve okul öncesi öğretmen adaylarının çok kültürlü eğitime yönelik toplam tutum puanları ile kültürlerarası duyarlılık toplam puanları incelendiğinde iki ölçek puanı arasında pozitif yönde anlamlı bir ilişki olduğu belirlenmiştir $(r=.463, p<.001)$. Ayrıca öğretmen adaylarının çok kültürlü eğitime yönelik toplam tutum puanları ile kültürlerarası duyarlılık toplam puanları arasında da pozitif yönlü anlamlı bir ilişki belirlenmiştir $(r=.568, p<.001 ; r=.365, p<.001)$. Sınıf ve okul öncesi öğretmenliği öğretmen adaylarının ölçeklerden aldıkları toplam puanlar arasında pozitif yönde bir ilişki olması, öğretmen adaylarının çok kültürlü eğitime yönelik tutumlarının arttıkça kültürlerarası duyarlılıklarının da arttığını göstermiştir.

Öğretmen adaylarının çok kültürlü eğitime yönelik tutumlarına ilişkin Mann-Whitney U testi sonuçları Tablo 4'te verilmiştir.

Tablo 4

Sınıf ve Okul Öncesi Öğretmenliği Öğretmen Adaylarının Çok Kültürlü Eğitime Yönelik Tutumlarına İlişkin Mann-Whitney U Testi Sonuçları

\begin{tabular}{|c|c|c|c|c|c|c|}
\hline Gruplar & $\mathrm{n}$ & $\begin{array}{l}\text { Siralar } \\
\text { Ortalamas1 }\end{array}$ & $\begin{array}{l}\text { Siralar } \\
\text { Toplamı }\end{array}$ & $\mathrm{U}$ & $\mathrm{Z}$ & $\mathrm{P}$ \\
\hline Sınıf Öğretmenliği & 110 & 106.08 & 11669.00 & & & \\
\hline $\begin{array}{l}\text { Okul Öncesi } \\
\text { Öğretmenliği }\end{array}$ & 103 & 107.98 & 11122.00 & 5564.000 & -.225 & .822 \\
\hline Toplam & 213 & & & & & \\
\hline
\end{tabular}

Tablo 4'deki Mann-Whitney U testine ilişkin bulgular öğretmen adaylarının çok kültürlü eğitime yönelik tutumları arasında anlamlı bir farklılığın olmadığını göstermiştir (Z=.225 ; p>.05). Gruplar sıra ortalamaları açısından incelendiğinde Okul Öncesi ve Sınıf Öğretmenliği öğretmen adaylarının çok kültürlü eğitime yönelik tutumları arasında istatistiksel olarak anlamlı farklılık tespit edilmemiştir.

Öğretmen adaylarının kültürlerarası duyarlılık düzeylerine ilişkin Mann-Whitney U testi sonuçları Tablo 5’te verilmiştir. 
Tablo 5

Sınıf ve Okul Öncesi Öğretmenliği Öğretmen Adaylarının Kültürlerarası Duyarlılık Düzeylerine İlişkin Mann-Whitney U Testi Sonuçları

\begin{tabular}{lllllll}
\hline Gruplar & $\mathrm{n}$ & $\begin{array}{l}\text { Siralar } \\
\text { Ortalaması }\end{array}$ & $\begin{array}{l}\text { Siralar } \\
\text { Toplamı }\end{array}$ & $\mathrm{U}$ & $\mathrm{Z}$ & $\mathrm{P}$ \\
\hline $\begin{array}{l}\text { Sinıf Öğretmenliği } \\
\begin{array}{l}\text { Okul Öncesi } \\
\text { Öğretmenliği }\end{array}\end{array} \mathrm{l}^{\text {Toplam }}$ & 103 & 101.12 & 11123.00 & & & \\
\hline
\end{tabular}

Tablo 5'deki Mann-Whitney U testine ilişkin bulgular Sınıf ve Okul Öncesi Öğretmenliği öğretmen adaylarının kültürlerarası duyarlılık düzeyleri arasında anlamlı bir farklı1ığın olmadığını göstermiştir $(\mathrm{Z}=-1.442 ; \mathrm{p}>.05)$. Öğretmen adaylarının sıra ortalamaları incelendiğinde, kültürlerarası duyarlılık düzeyleri arasında istatistiksel olarak anlamlı farklılığın olmadığı saptanmıştır.

Öğretmen adaylarının çok kültürlü eğitime yönelik tutumlarının büyüdükleri yerleşim yerine göre Kruskall Wallis-H testi sonuçları Tablo 6' da verilmiştir.

Tablo 6

Sınıf ve Okul Öncesi Öğretmenliği Öğretmen Adaylarının Çok Kültürlü Eğitime Yönelik Tutumlarının Büyüdükleri Yerleşim Yerine Göre KWH Testi Sonuçları

\begin{tabular}{|c|c|c|c|c|c|c|}
\hline Gruplar & Yerleşim Yeri & $\mathrm{n}$ & $\begin{array}{l}\text { Sira } \\
\text { Ortalamas1 }\end{array}$ & sd & KWH & $\mathrm{p}$ \\
\hline \multirow{4}{*}{$\begin{array}{l}\text { Sınıf } \\
\text { Öğretmenliği }\end{array}$} & İl & 46 & 59.37 & \multirow{4}{*}{2} & \multirow{4}{*}{1.734} & \multirow{4}{*}{.420} \\
\hline & İlçe & 48 & 54.45 & & & \\
\hline & Köy & 16 & 47.53 & & & \\
\hline & Toplam & 110 & & & & \\
\hline \multirow{4}{*}{$\begin{array}{l}\text { Okul Öncesi } \\
\text { Öğretmenliği }\end{array}$} & İl & 49 & 52.55 & \multirow{4}{*}{2} & \multirow{4}{*}{.504} & \multirow{4}{*}{.777} \\
\hline & İlçe & 40 & 53.15 & & & \\
\hline & Köy & 14 & 46.79 & & & \\
\hline & Toplam & 103 & & & & \\
\hline
\end{tabular}

Tablo 6'da görüldüğü gibi sınıf öğretmenliği öğretmen adaylarının çok kültürlü eğitime yönelik tutumlarında büyüdükleri yerleşim yerine göre anlamlı bir farklılığa yol açmadığ saptanmıştır $\left(\mathrm{KWH}_{(2)}=1.734 ; \mathrm{p}>.05\right)$. Ayrıca okul öncesi öğretmenliği öğretmen adaylarının da çok kültürlü eğitime yönelik tutumlarına ilişkin büyüdükleri yerleşim yerine göre yapılan KWH testi sonucunda da gruplar arasında istatistiksel olarak farklılığa rastlanmamıştır. $\left(\mathrm{KWH}_{(2)}=.504\right.$; p>.05).

Öğretmen adaylarının kültürlerarası duyarlılık düzeylerinin büyüdükleri yerleşim yerine göre Kruskall Wallis-H testi sonuçları Tablo 7'de verilmiştir.

Tablo 7 incelendiğinde sınıf öğretmenliği öğretmen adaylarının kültürlerarası duyarlılık düzeylerinin büyüdükleri yerleşim yerine göre anlamlı bir farklılığa yol açmadığı belirlenmiştir $\left(\mathrm{KWH}_{(2)}=.219 ; \mathrm{p}>.05\right)$. Ayrıca okul öncesi öğretmenliği öğretmen adaylarının kültürlerarası duyarlılık düzeylerine ilişkin büyüdükleri yerleşim yerine göre uygulanan KWH testi sonucunda da gruplar arasında anlamlı bir farklılığa rastlanmamıştır. $\left(\mathrm{KWH}_{(2)}=4.241 ; \mathrm{p}>.05\right)$. Okul öncesi öğretmenliği öğretmen adaylarının kültürlerarası duyarlılık düzeylerinde büyüdükleri yerleşim yeri değişkenine göre anlamlı bir farklılık tespit edilmemesine rağmen, büyüdüğü yerleşim yeri 
"İl" olan öğretmen adaylarının sıra ortalama puanlarının "İlçe" ve "Köy" olarak belirten öğretmen adaylarının sıra ortalama puanlarından yüksek olduğu görülmektedir. Bu durum ilde büyümüş okul öncesi öğretmen adaylarının kültürlerarası duyarlılık düzeylerinin daha yüksek olduğu şeklinde yorumlanabilir. Aynı durum sınıf öğretmenliği öğretmen adayları için de söylenebilir.

Tablo 7

Sınıf ve Okul Öncesi Öğretmenliği Öğretmen Adaylarının Kültürlerarası Duyarlılık Düzeylerinin Büyüdükleri Yerleşim Yerine Göre KWH Testi Sonuçları

\begin{tabular}{lllllll}
\hline Gruplar & Yerleşim Yeri & $\mathrm{n}$ & $\begin{array}{l}\text { Sira } \\
\text { Ortalaması }\end{array}$ & sd & KWH & $\mathrm{p}$ \\
\hline \multirow{3}{*}{ Sınıf } & İl & 46 & 56.76 & & & \\
Öğretmenliği & İlçe & 48 & 55.30 & 2 & .219 & .896 \\
& Köy & 16 & 52.47 & & & \\
& Toplam & 110 & & & & \\
& İl & 49 & 58.21 & & & \\
Okul Öncesi & İlçe & 40 & 47.39 & & & \\
Öğretmenliği & Köy & 14 & 43.43 & 2 & 4.241 & \\
& Toplam & 103 & & & & \\
& & & & & & \\
\hline
\end{tabular}

\section{Tartışma / Sonuç ve Öneriler}

Araştırma sonuçlarına göre, öğretmen adaylarının çok kültürlü eğitime yönelik tutumlarının ve kültürlerarası duyarlılık düzeylerinin yüksek olduğu ve bu iki tutum arasında pozitif yönde anlamlı bir ilişki olduğu saptanmıştır. Kaya ve Söylemez (2014) çokkültürlülük ve çokkülttürlü eğitim üzerine yaptığı çalıșmada, çokkültürlü eğitime ilișkin olarak öğretmenlerin olumlu görüşlerinin olduğunu belirlemişlerdir. Öğretmen adayları ile yapılan bir diğer çalışmada öğretmen adaylarının çok kültürlü eğitimi kabul ettikleri ve kendilerini bu konuda yeterli hissettikleri saptanmış ve öğretmen adaylarının çokkültürlü eğitime yönelik olarak herhangi bir eğitim almadıkları da belirlenmiştir (Demir ve Başarır, 2013). Ngai (2004), küçük yaşlardan itibaren çocukların eğitiminde başarıya ulaşmak için öğretmen adaylarının çok kültürlü eğitime ilişkin olarak nitelikli bir eğitimden geçmeleri gerektiğini ifade etmiştir. Öğretmen adaylarının çokkültürlü eğitime yönelik tutumlarının ve kültürlerarası duyarlılık düzeylerinin yüksek olması, adayların öğretmen olduklarında farklı kültürlere yönelik olarak nitelikli eğitim vermeleri açısından olumlu bir sonuç olarak görülebilir. Özellikle okul öncesi ve sınıf öğretmenliği gibi erken dönemde çocuklara eğitim veren öğretmenlerin, bu tutumlara yönelik uygulamalara yer vermeleri çocukların toplum içinde de farklılıklara saygı duymaları açısından önemlidir.

Öğretmen adaylarının kendi bölümleri içinde çok kültürlü eğitime yönelik tutumları ve kültürlerarası duyarlılık düzeyleri arasında anlamlı bir farklılık belirlenmemiştir. Tortop (2014) çok kültürlü eğitime yönelik olarak öğretmen adaylarının tutumlarını araştırdığı çalışmasında, öğretmen adaylarının bölümlerinin çokkültürlü eğitime yönelik tutumlarında etkisi olmadığını saptamıştır. Benzer olarak Rengi ve Polat (2014) çalışmalarında öğretmenlerin kültürlerarası duyarlılık düzeylerinin yüksek olduğunu tespit etmişlerdir. Yapılan araştırmalar öğretmen adaylarının cinsiyetlerine göre de kültürlerarası duyarlılık düzeylerinde farklılık olmadığını göstermektedir (Bayles, 2009; Hammer, Bennett ve Wisemann, 2003; Polat ve Barka, 2012; Polat ve Barka, 2012; Üstün, 2011; Yılmaz ve Göçen, 2013). Çoban, Karaman ve Doğan (2010) yaptıkları çalışmada, tezsiz yüksek lisans yapan ögretmen adaylarının farklı kültürlere bakış açılarının olumlu olduğunu saptamışlardır. Öğretmen adaylarının öğrenim gördükleri bölümlere 
göre çok kültürlü eğitime yönelik tutumları ve kültürlerarası duyarlılık düzeyleri arasında farklılığın olmamasının nedenleri olarak, sınıf ve okul öncesi öğretmenliği programlarının Temel Eğitim kapsamında olması ve araştırma kapsamındaki öğretmen adaylarının küçük yaş gruplarıyla çalışacak olmaları gösterilebilir. Ayrıca diğer branşlarda öğrenim gören öğretmen adaylarıyla yapılan araştırmalarda da farklılı̆̆ın olmaması, öğretmen adaylarının eğitime yönelik benzer dersleri alıyor olmalarından kaynaklanabilir.

Sınıf ve okul öncesi öğretmenliği öğretmen adaylarının çok kültürlü eğitime yönelik tutumlarının ve kültürlerarası duyarlılık düzeylerinin büyüdükleri yerleşim yerine göre anlamlı bir farklılığa yol açmadığı tespit edilmiştir. Sınıf ve okul öncesi öğretmenliği öğretmen adaylarının kültürlerarası duyarlılık düzeylerinde büyüdükleri yerleşim yeri değişkenine göre anlamlı bir farklılık tespit edilmemesine rağmen, büyüdüğ̈̈ yerleşim yeri "İl” olan öğretmen adaylarının puanlarının "İlçe" ve "Köy" olarak belirten öğretmen adaylarının puanlarından yüksek olduğu belirlenmiştir. Asada ve diğerlerinin (2003) çok kültürlü eğitim konusunda yaptıkları araştırma sonucunda, köylerde yaşayan bireylerin, daha az olumlu görüşe sahip oldukları tespit edilmiştir. Üstün (2011) yaptığı araştırmada, ilde yetișen öğretmen adaylarının kültürlerarası duyarlılık düzeylerinin köyde ve ilçede yetişen öğretmen adaylarına göre anlamlı bir şekilde daha yüksek olduğunu saptamıştır. Yazıcı, Başol ve Toprak (2009) ise öğretmenlerin çokkültürlü eğitime yönelik tutumlarını incelediği araştırmada, öğretmenlerin çokkültürlü veya tekkültürlü bir çevrede eğitim yaşantılarının geçmesinin tutumlarını farklılaştırdı̆̆ını belirlemişlerdir. Demir ve Başarır (2013) çok kültürlü yeterlik algılarını etkileyen etmenlerden birinin yerleşim yeri olduğu sonucuna ulaşılan çalışmalarında, illerden gelen öğretmen adaylarının kendilerini çok kültürlü eğitim açısından daha yeterli bulduklarını tespit etmiştir. Bu araştırmada sınıf ve okul öncesi öğretmenliği öğretmen adaylarının çok kültürlü eğitime yönelik tutumlarının ve kültürlerarası duyarlılık düzeylerinin büyüdükleri yerleşim yerine göre anlamlı bir farklılığa yol açmadığı belirlenmekle beraber, ortalamalar incelendiğinde diğer araştırma sonuçlarına benzer olarak ilde büyüyen öğretmen adaylarının tutumlarının daha yüksek olduğu belirlenmiş̧ir. $\mathrm{Bu}$ durumun illerde farklı kültürlerin bir arada yaşamasından kaynaklandığ düşünülmektedir.

$\mathrm{Bu}$ sonuçlar doğrultusunda aşağıdaki öneriler sunulabilir:

- Meslekteki öğretmenlere hizmet içi eğitimler, öğretmen adaylarına ise lisans eğitimi sırasında çokkültürlü eğitime yönelik tutumlarının ve kültürlerarası duyarlılık düzeylerinin arttırılmasını sağlayan uygulamalara da yer verilebilir.

- Çokkültürlülük ve kültürlerarası duyarlılık çalışmalarının arttırılması, nitel çalışmalarla beraber derinlemesine araştırmalara ve deneysel çalışmalara yer verilmesi konunun öneminin daha iyi anlaşılmasını sağlanabilir.

- Eğitimin okul öncesi dönemden başladığı düşünülerek, tüm kademelerde programda yer alan ders içeriklerine çokkültürlülük, farklılıklara saygı duyma gibi evrensel özelliklerin geliştirilmesine yönelik bilgi ve becerilere ağırlık verilebilir.

\section{Kaynaklar}

APA (2002). Guidelines on multicultural education, training, research, practice, and organizational change for psychologists. Erişim adresi: http://www.apa.org/pi/oema/resources/policy/multicultural-guidelines.aspx

Asada, H., Swank, E. ve Goldey, G. T. (2003). The acceptance of a multicultural education among appalachian college students. Research in Higher Education, 44, 99-120.

Bademci, V. (2006). Güvenirliği doğru anlamak ve bazı klişeleri yıkmak: bilinenlerin aksine, cronbach'ın alfa katsayıs1, negatif ve-1'den küçük olabilir. Inönü Üniversitesi Eğitim Fakültesi Dergisi, 7(12), 3-26.

Balay, R. (2004). Küreselleşme, bilgi toplumu ve eğitim. Ankara Üniversitesi Eğitim Bilimleri Fakültesi Dergisi, 37(2), 61-82.

Başbay, A. ve Kağnıcı, D. Y. (2011). Çokkültürlü yeterlik algıları ölçeği: bir ölçek geliştirme çalışması. Ĕgitim ve Bilim, 36(161), 199-212. 
Bayles, P. P. (2009). Assesing the intercultural sensitivity of elementary teachers in bilingual schools in texas school district (Unpublished $\mathrm{PhD}$ Thesis). The University of Minnesota.

Chen, G. ve Starosta, W. J. (2000). The development and validation of the intercultural sensitivity scale. Paper presented at the Annual Meeting of the National Communication Association. Seattle, WA.

Cırık, İ. (2008). Çok kültürlü eğitim ve yansımaları. Hacettepe Eğitim Fakültesi Dergisi. 34, 27 40.

Çoban, A. E., Karaman, N. G. ve Doğan, T. (2010). Öğretmen adaylarının kültürel farklılıklara yönelik bakış açılarının çeşitli demografik değişkenlere göre incelenmesi. Abant İzzet Baysal Üniversitesi Eğitim Fakültesi Dergisi, 10(1), 125-131.

Demir, S. ve Başarır, F. (2013). Çok kültürlü eğitim çerçevesinde öğretmen adaylarının özyeterlik algilarının incelenmesi. International Journal of Social Science, 6(1), 609641. doi.org/10.9761/JASSS_489

Gay, G. (2002). Preparing for culturally responsive teaching. Journal of Teacher Education, 53, 106-116.

Hammer, M. R., Bennett, M. J. ve Wiseman, R. (2003). Measuring intercultural sensitivity: the intercultural development inventory. International Journal of Intercultural Relations. 27, 421-443.

Jimenez, M. R. M., Guzmán, N. A. ve Maxwell, G. M. (2014). South texas teachers' and leaders' perceptions of multicultural education. Journal of Instructional Pedagogies, 15(1), 19.

Kaya, Y. ve Söylemez, M. (2014). Öğretmenlerin çokkültürlülük ve çokkültürlü eğitim hakkındaki görüşlerinin belirlenmesi: (Diyarbakır örneği). Dicle Üniversitesi Sosyal Bilimler Enstitüsü Dergisi, 6(11). 128-148.

Kengwee, J. (2010). Fostering cross cultural competence in preservice teachers through multicultural education experiences, Early Childhood Education, 38, 197-204 doi.org.10.1007/s10643-010-0401-5

Mahiroğulları, A. (2005). Küreselleşmenin kültürel değerler üzerine etkisi. Sosyal Siyaset Konferanslar Dergisi, 50, 1275-1288.

Neuharth-Pritchett, S., Reiff, J. C. ve Pearson, C. A. (2001). Through the eyes of preservice teachers: Implications for the multicultural. Journal of Research in Childhood Education, 15(2), 256-269.

Ngai, P. B. (2004). A reinforcing curriculum and program reform proposal for 21 st century teacher education: vital first steps for advancing K-12 multicultural education, Equity \& Excellence in Education, 37(4), 321-331.

Özdemir, M. ve Dil, K. (2013). Öğretmenlerin çok kültürlü eğitime yönelik tutumları: Çankırı ili örneği. Ankara Üniversitesi Eğitim Fakültesi Dergisi, 46(2), 215-232.

Polat, S. (2009). Öğretmen adaylarının çok kültürlü eğitime yönelik kişilik özellikleri, International Online Journal of Educational Sciences, 1(1), 154-164.

Polat, S. ve Barka, T. O. (2014). Preservice teachers' intercultural competence: Acomparative study of teachers in Switzerland and Turkey. Eurasian Journal of Educational Research, 54, 19-38. doi.org/10.14689/ejer.2014.54.2

Rengi, Ö. ve Polat, S. (2014). Sınıf öğretmenlerinin kültürel farklılık algıları ve kültürlerarası duyarl111klar1. Zeitschrift für die Welt der Türken/Journal of World of Turks, 6(3), 135156.

Sharma, S. (2011). Multicultural education: teachers' perceptions and preparation. Journal of College Teaching \& Learning (TLC), 2(5), 53-63.

Smolen, L., A., Colville-Hall, S., Liang, X. ve Mac Donald, S. (2006). An emprical study of college of education faculty's perceptions, beliefs, and commitment to the teaching of diversity in teacher education programs at four urban universities. The Urban Review, $38,45-61$. 
Tortop, H. S. (2014). Öğretmen adaylarının üstün yetenekli ve çok kültürlü eğitime ilişkin tutumları. Üstün Yetenekliler Eğitimi ve Araştırmaları Dergisi (UYAD), 2(2), 16-26.

Ünlü, İ. ve Örten, H. (2013). Öğretmen adaylarının çokkültürlülük ve çokkültürlü eğitime yönelik algılarının incelenmesi. Dicle Üniversitesi Ziya Gökalp Eğitim Fakültesi Dergisi, 21, 287-302.

Üstün, E. (2011). Öğretmen adaylarının kültürlerarası duyarlılık ve etnikmerkezcilik düzeylerin etkileyen etmenler (Yayımlanmamış yüksek lisans tezi). Yıldız Teknik Üniversitesi, İstanbul.

Van Oudenhoven, J. P. ve Van der Zee, K. I. (2002). Predicting multicultural effectiveness of international students: the multicultural personality questionnaire. International Journal of Intercultural Relations, 26(6), 679-694.

Yavuz, G. ve Anıl, D. (2010). Öğretmen adayları için çok kültürlü eğitime yönelik tutum ölçeği: Güvenirlik ve geçerlik çalışması. In International Conference on New Trends in Education and Their Implications, 11-13.

Yazıcı, S., Başol, G., ve Toprak, G. (2009). Öğretmenlerin çokkültürlü eğitim tutumları: bir güvenirlik ve geçerlik çalışması. Hacettepe Üniversitesi Eğitim Fakültesi Dergisi, 37(37), 229-242.

Yılmaz, F. ve Göçen, S. (2013). Sınıf öğretmeni adaylarının kültürlerarası duyarlılık hakkındaki görüşlerinin farklı değişkenlere göre incelenmesi. Adlyaman Üniversitesi Sosyal Bilimler Enstitüsü Dergisi, (15), 373-392. doi.org/10.14520/adyusbd.649

\section{Extended Abstract}

\section{Introduction}

In some schools where different cultures can be found together, teachers and students from different cultures continue their educational lives. There may be some problems in these environments because of cultural differences. The most important thing is to have an education where cultural differences are taken into consideration and respected. The most important task is on the shoulders of teachers. Because the ones who run education programs, create educational environments and evaluating these are none other than teachers (Polat, 2009, Rengi \& Polat, 2014). Researches show that many teachers who lack adequate qualifications can't create appropriate learning environments for students from different cultures (Cırık, 2008; Çoban, Karaman \& Doğan, 2010; Gay, 2002; Keengwe, 2010; Neuharth-Pritchett, Reiff \& Pearson 2001; Polat, 2009). According to results of a study done with members of various education faculties, faculty members come across students from various cultures and they believe in necessity of culturally sensitive education programs but they have problems in implementing them (Smolen, Colville-Hall, Liang \& Mac Donald, 2006). It is thought that giving sensitivity to teachers and teacher candidates about students from different cultures and giving skills to organize learning environments are important for eliminating these problems. So, the aim of this study is to investigate the relationship between the attitudes of of preschool and classroom teacher candidates towards multicultural education and their intercultural sensitivity. Another aim is to analyze the attitudes of classroom and preschool teacher candidates towards multicultural education according to their departments and surrounding environment and determine if there is a difference between their intercultural sensitivities.

\section{Method}

General screening model was used in the research carried out to determine the relationship between the attitudes of classroom and preschool teacher candidates towards multicultural education and their intercultural sensitivity levels. The sample of the research was formed of Classroom $(\mathrm{N}=110)$ and Preschool $(\mathrm{N}=103)$ teacher candidates studying at Uludağ University Faculty of Education. Statistical calculations were made on the data of 213 teacher candidates. Personal Information Form, Multicultural Education Attitude Scale that was adapted into Turkish by Yazıcı, Başol and Toprak (2009) and Intercultural Sensitivity Scale that was adapted 
by Üstün (2011) were used in the research. Analysis of data was carried out in two phases. It was evaluated in terms of normality and sub-problems were analyzed in the second phase. The distribution was determined to be normal as a result of Kolmogorov-Smirnov normality test. Therefore, Kruskall Wallis- $\mathrm{H}(\mathrm{KWH})$ which is a test without a parameter was used instead of variance analysis and Mann Whitney U (MWU) test was used instead of t-test. Also, correlation analysis was used in order to determine the relationship between the attitudes of classroom and preschool teacher candidates towards multicultural education and their intercultural sensitivity levels.

\section{Results and Discussion}

It was determined as a result of the study that the attitudes of classroom and preschool teacher candidates towards multicultural education and their intercultural sensitivities are high and there is a significant relation between these two attitudes in a positive way. Kaya and Söylemez (2014) also stated in their research on multiculturalism and multicultural education that teachers generally express positive opinions about multicultural education. Demir and Başarır (2013) determined in their research that teacher candidates accept multicultural education and they feel sufficient on the topic and teacher candidates don't have any education regarding multicultural education. Ngai (2004) also stated that teacher candidates should have a qualified education on multicultural education in order to give a successful education to children starting from early ages.

A significant difference wasn't found between the attitudes of classroom and preschool teacher candidates towards multicultural education and their intercultural sensitivity levels. Tortop (2014) also determined in his research on gifted children and attitudes towards multicultural education that departments of teacher candidates don't have any effect on the attitudes of teacher candidates towards multicultural education. Similarly, Rengi and Polat (2014) stated that intercultural sensitivity levels of teachers are high. Other studies show that there is not a difference on intercultural sensitivity levels of teacher candidates in terms of genders (Bayles, 2009; Hammer, Bennett \& Wisemann, 2003; Polat \& Barka, 2012; Üstün, 2011; Y1lmaz \& Göçen, 2013). Çoban, Karaman and Doğan (2010) determined in their research that teacher candidates doing non-thesis master's degree have positive attitudes towards different cultures.

It was determined that attitudes of classroom and preschool teacher candidates towards multicultural education and their intercultural sensitivities don't cause any significant different in terms of their surrounding environments. Although a significant difference wasn't found at intercultural sensitivity levels of classroom and preschool teacher candidates in terms of their surrounding environments, it was determined that scores of teacher candidates who grow in "cities" are higher than the scores of teacher candidates who grow in "districts" and "villages". In consequence of a research done by Asada et al. (2003) it was determined that individuals who live in villages have less positive opinions about multicultural education. Üstün (2003) determined in a research that sensitivity levels of teacher candidates who grow up in cities are significantly higher than teacher candidates from villages and districts. On the other hand, Yazıc1, Başol and Toprak (2009) stated in their research on the attitudes of teachers towards multicultural education that the place where teachers have their education and whether they are multicultural or monocultural environments have great impacts on their attitudes. Demir and Başarır (2013) determined in their research showing that one of the factors effecting multicultural competence perceptions is residential area and teacher candidates from urban areas find themselves more sufficient in terms of multicultural education. 